\title{
Susceptibility of maize genotypes to Rhyzopertha dominica (F.)
}

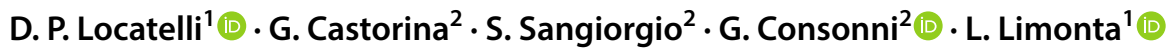

Received: 18 April 2019 / Accepted: 12 July 2019 / Published online: 18 July 2019

(c) The Author(s) 2019

\begin{abstract}
This work examined the survival of Rhyzopertha dominica on maize kernels differing either for specific traits or for their genetic background. Maize traits comprised endosperm starch composition, and accumulation of pigments, i.e., carotenoids and anthocyanins, in the aleurone, while maize genotypes included the B73 reference line, the high oil content RAlexo line and the commercial variety Zea mays everta (popcorn). Kernels of the different genotypes were classified according to the endosperm texture. The number of adults of $R$. dominica developing from neonate larvae on both whole and sectioned kernels was measured. Differences were only observed in experiments with whole kernels. The lowest value was observed for the B73 line, and the highest for the popcorn variety. These two genotypes have the lowest and highest proportions of vitreous endosperm, respectively. In our experimental conditions, variations in the insect attack were observed in different lines, thus indicating that the insect-kernel interaction is influenced by quantitative more than single-gene traits.
\end{abstract}

Keywords Lesser grain borer $\cdot$ Larvae $\cdot$ Zea mays $\cdot$ Endosperm mutants $\cdot$ Maize seed traits

\section{Introduction}

Rhyzopertha dominica (F.) (Coleoptera, Bostrichidae) is one of the economically most important beetles infesting cereal grains on a worldwide scale (www.plantwise.org), and its feeding can reduce kernels to the pericarp (Winterbottom 1922; Campbell and Sinha 1976).

Females lay eggs on the surface and newly born larvae drill into the kernels, preferring breaks or the germ area where the covering testa is loose (Birch 1945a). On

Electronic supplementary material The online version of this article (https://doi.org/10.1007/s41348-019-00250-8) contains supplementary material, which is available to authorized users.

L. Limonta

lidia.limonta@unimi.it

D. P. Locatelli

daria.locatelli@unimi.it

G. Consonni

gabriella.consonni@unimi.it

1 Department of Food, Environmental and Nutritional Sciences (DeFENS), Università degli Studi di Milano, Via Celoria 2, 20133 Milan, Italy

2 Department of Agricultural and Environmental Sciences Production, Landscape, Agroenergy (DiSAA), Università degli Studi di Milano, Via Celoria 2, 20133 Milan, Italy damaged kernels, first instar larvae mortality decreases (Birch 1945a, b; Howe 1950; Breese 1960), and progeny production increases (Throne et al. 2000), while hardness of kernels has no effect on $R$. dominica reproduction (Bhatia and Gupta 1969; Amos et al. 1986; Sinha et al. 1988; Towes et al. 2000). This insect can also develop on twigs of different plants, legume seeds and various other substances (Edde 2012). It can also develop on milled media, such as semolina, but in this case, it needs at least a 6-mm layer (Limonta et al. 2011).

Stored product beetles are resistant to many grain protectants: the first records date back to 1965 (Parkin 1965). In particular, resistance of $R$. dominica was recorded to organophosphates and pyrethroids (Navarro et al. 1986; Zettler and Cuperus 1990; Lorini and Galley 1996, 1999; Guedes et al. 1996, 1997; Collins 2006), phosphine (Bell et al. 1977; Herron 1990; Zettler and Cuperus 1990; Lorini and Collins 2006; Opit et al. 2012; Collins et al. 2017), juvenile hormone analogues (Collins et al. 1993; Collins 1998; Lorini and Galley 1999; Daglish et al. 2013). The selection of host-plant genotypes that restrain insect pest development could be an alternative to treatment with insecticides for any cereal crops that suffer from grain damage by postharvest pests. New sources of resistance to the insects would be useful in breeding programs; however, this approach has not yet been considered as a method of control. 
In rice, kernel soundness and integrity are generally considered the most important characters for conferring resistance to $R$. dominica infestation. A correlation between cracked and split hulls and susceptibility was observed (Chanbang et al. 2008a, b; Kavallieratos et al. 2012), and varieties with thicker hulls have been shown to be more tolerant (Chanbang et al. 2008a). Moreover, a work conducted on African varieties has established that hardness and husk protection can confer tolerance to $R$. dominica (Chougourou et al. 2013), while the work of Astuti et al. (2013) conducted in Indonesia has shown that high phenolic content and hardness can increase resistance to $R$. dominica infestation. In wheat, susceptibility is negatively correlated with kernel hardness and is instead positively correlated with the percentage of total protein (Watts and Dunkel 2003).

Studies on $R$. dominica effects on maize varieties mostly go back to the 1990s. These studies examined local varieties and hybrids cultivated in India (Pandey and Singh 1974; Singh and Pandey 1977; Kurdikeri et al. 1994, 1995) and in Egypt (El Halfawy and Hassan 1978) and found that some of them were less susceptible to $R$. dominica. Although they did not provide an explanation for the different susceptibility, they provide a first indication of the existence of variability for this trait in the maize germplasm. The analysis of additional genotypes will show whether other sources of resistance are present in different maize germplasm collections and will also be of help in unraveling the biochemical characteristics that confer tolerance to the host plant.

The maize seed comprises two major compartments: the embryo and the endosperm (Consonni et al. 2005). The embryo represents the next sporophytic generation, while the endosperm, which is the largest seed compartment, provides nutrients and signals for embryo development and seedling germination. The maize endosperm comprises different domains, among which are the central region that accumulates starch and reserve proteins, and the aleurone, which is the outer layer of the endosperm ( $\mathrm{Li}$ and Berger 2012). Starch is composed of two types of glucose homopolymers, linear amylose and branched amylopectin, while proteins include mainly zeins, a unique storage protein found only in cereals. Several genes have been described that are involved in starch biosynthesis. Among them is the Sugaryl (Sul) gene (James et al. 1995) that encodes an isoamylase that hydrolyzes $\alpha-1,6$ bonds in amylopectin. Mutants in this gene change starch composition, causing a decrease in amylopectin and an increase in the more highly branched and soluble polymer, phytoglycogen. As a consequence, mutants show changes in endosperm texture and seed appearance.

The aleurone layer is characterized by the accumulation of secondary metabolites that include important antioxidant compounds. In particular, genotypes, anthocyanins and carotenoids accumulate, thus conferring on the kernels the dark red and orange colored appearance, respectively (Dooner et al. 1991; Tan et al. 1997).

The susceptibility of maize lines, differing for specific seed traits and for their genetic constitution, to $R$. dominica was examined in this work. The general aim was to identify genotypes showing resistance to the attack. This information will be a prerequisite for developing resistant varieties useful in storage of products of organic agriculture, whose regulation precludes the use of pesticides in both field and storage. Moreover, resistant varieties allow the farmer to save the cost of using controlled atmospheres, which are unaffordable in developing countries.

\section{Materials and methods}

\section{Plant material}

The endosperm-related mutants and inbred lines used in this study were provided by the Maize Genetics Cooperation Stock Center (http://maizecoop.cropsci.uiuc.edu/). Plants were grown and propagated in an open field at the University of Milan. The harvested seeds were dried to about 12-13\% moisture content and stored at room temperature.

Mutant lines were propagated through selfing heterozygous plants; tests were performed with homozygous mutants and related wild-type kernels selected from $F_{2}$ segregating ears. Inbred lines were propagated via siblings mating. The seeds of the popcorn variety (Zea mays everta) were purchased at a local supermarket.

\section{Maize genotypes description}

The B73 line, developed at Iowa State University (Russell 1972), exhibits high yield, and it is the most used laboratory accession and the main source of commercially important germplasm. Its genome sequence was released in 2009 (Schnable et al. 2009). The RAlexo genetic stock, also known as Alexander High Oil Synthetic, is the result of a selection carried out at the University of Illinois for grain with high oil content (http://www.maizegdb.org, Gerdes et al. 1993; Goldman et al. 1994).

Popcorn (Zea mays everta) is one of the favorite maize varieties around the world. Its commercialization started in the 1880s (Erwin 1949), and the modern varieties are the result of modern breeding methods which have improved the desired characters, such as flavor and pericarp strength.

The sugaryl (sul) gene, located on the short arm of chromosome 4, encodes isoamylase-type starch debranching 1 enzyme, belonging to the family of $\alpha$-amylase starch hydrolytic enzymes (Pan and Nelson 1984). Loss of sul gene function results in the accumulation of sugars and the highly branched water-soluble polysaccharide phytoglycogen in the 
endosperm. The endosperm of mutant seeds is wrinkled and translucent when dry, sweet at the milk stage.

Su1 and su1 kernels show accumulation of anthocyanin pigments in the region surrounding the embryonic axis, due to the presence of an allele of the anthocyaninless 1 (al) gene, referred to as al-eap (embryonic axis profile) (Gavazzi et al. 2004).

The yellow endosperm1 ( $y 1)$ gene, located on the long arm of chromosome 6 , controls the production of the enzyme phytoene synthase (PSY), involved in the first step of the biosynthesis of carotenoids in the endosperm (Buckner et al. 1996). Homozygous $y 1 / y 1$ mutant seeds, characterized by low carotenoids content in the endosperm, can be easily distinguished on segregating ears for their pale yellow color.

Colored seeds were from the W23 line carrying the dominant alleles required for anthocyanin pigmentation in the aleurone, i.e., $A 1, C l$ and $R 1$ alleles; colorless seeds were from the same line.

\section{Insect rearing}

Rhyzopertha dominica was reared on maize kernels at $29 \pm 1{ }^{\circ} \mathrm{C}, 70 \pm 5 \%$ R.H. and a photoperiod of $16: 8$ (light/ dark). Mixed maize kernels, $450 \mathrm{~g}$, and 100 adults were put in a glass jar $(13 \mathrm{~cm} \varnothing ; 20 \mathrm{~cm}$ height $)$ with a lid provided with a hole $(3 \mathrm{~cm} \varnothing)$ closed by a stainless steel wire mesh to allow gaseous exchange. Adults were allowed to oviposit for three days and were then removed, in order to obtain coeval adults progeny.
To collect eggs, $20 \mathrm{~g}$ of kernels and 20 coeval adults were put in a Petri dish, with the bottom covered with black cardboard. After three days, kernels and adults were removed from the petri dish and the eggs were daily checked to collect first instar larvae characterized by a terminal median spine.

\section{Tests}

The tests were carried out by placing 40 maize kernels in glass containers $(35 \mathrm{~mm} \varnothing$; height $20 \mathrm{~mm}$ ) with 20 first instar larvae, 0-24 h old. Such containers, closed with a net (120 mesh) to provide ventilation, were placed in an incubator at $29 \pm 1{ }^{\circ} \mathrm{C}, 70 \pm 5 \%$ R.H. and $16 \mathrm{~h}$ of light alternating with $8 \mathrm{~h}$ of darkness. For each of the five maize genotypes, tests were carried out with 40 entire kernels and with 40 longitudinally sectioned kernels. Four replicates were carried out for each test.

To analyze the effect of starch composition on $R$. dominica attack, insect development in presence of seeds with an altered starch composition (sul/sul; Fig. 1) was compared with insect development in the presence of wild-type seeds obtained from selfing either homozygous (Sul/Sul) or heterozygous (Sul/-) $F_{1}$ plants. The effect of pigment presence was analyzed by comparing seeds accumulating carotenoids (Yl/-) or anthocyanin (W23 ACR-Colored) with sibling seeds devoid of pigment, i.e., $y 1 / y 1$ and colorless seeds (W23 ACR - colorless), respectively. Tests were carried out on both whole and sectioned kernels, and the number of adults which emerged was recorded.
Fig. 1 Phenotypic diversity of kernels used in this work. Kernels of $s u 1$ and $y 1$ mutant and relative wild-type genotypes and of colorless and colored W23 seeds (a) and inbred lines (b)
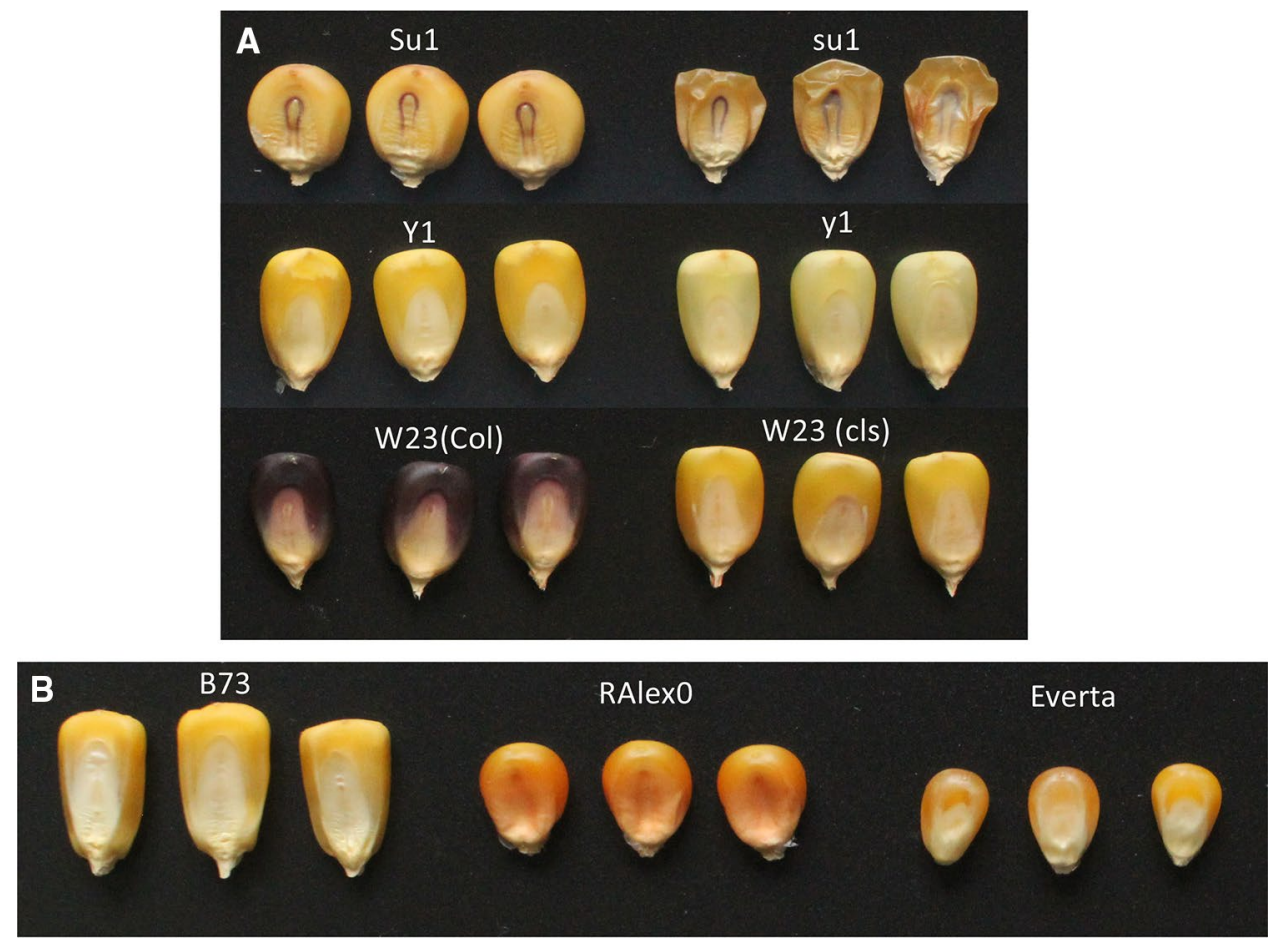
Table 1 Adults of Rhyzopertha dominica $( \pm \mathrm{SE})$ emerged from the whole and sectioned Sul wild-type (Sul/Sul and Sul/-) versus homozygous sul/sul mutant kernels

\begin{tabular}{llll}
\hline Genotype & Kernel phenotype & Whole & Sectioned \\
\hline Sul/Sul & Wild type & $3.2 \pm 1.25$ & $13.5 \pm 0.96$ \\
Sul/- & Wild type & $4.2 \pm 0.48$ & $10.5 \pm 0.87$ \\
sul/sul & Sugary-wrinkled & $5.7 \pm 1.03$ & $11.5 \pm 1.19$ \\
\hline
\end{tabular}

Anova: whole grain $F_{2,9}=1.664 P=0.243$ n.s.; sectioned grain $F_{2,9}=2.27 P=0.159$ n.s

Table 2 Adults of Rhyzopertha dominica $( \pm \mathrm{SE})$ emerged from the whole and sectioned Y1 wild-type (Y1/-) versus homozygous y1/yl mutant kernels

\begin{tabular}{llll}
\hline Genotype & Kernel phenotype & Whole & Sectioned \\
\hline$Y 1 /-$ & Wild type-yellow & $1.2 \pm 0.63$ & $12.0 \pm 1.47$ \\
$y 1 / y 1$ & Mutant-white & $2.2 \pm 0.25$ & $12.5 \pm 1.55$
\end{tabular}

Student's $t$ test: whole $t=1.477$ n.s; sectioned $t=0.234$ n.s

Table 3 Adults of Rhyzopertha dominica $( \pm \mathrm{SE})$ emerged from the whole and sectioned W23 ACR colored versus colorless kernels

\begin{tabular}{llll}
\hline Genotype & Kernel phenotype & Whole & Sectioned \\
\hline W23 & Colored & $2.7 \pm 0.48$ & $8.2 \pm 0.48$ \\
W23 & colorless & $4.5 \pm 1.04$ & $9.2 \pm 2.21$ \\
\hline
\end{tabular}

Student's $t$ test: whole $t=1.528 \mathrm{n} . \mathrm{s}$; sectioned $t=0.442 \mathrm{n} . \mathrm{s}$

\section{Data analysis}

The number of emerged adults and the days from the beginning of the test were recorded. Data, when normally distributed, were submitted to one-way ANOVA, LSD test and Student's $t$ test $(\alpha=0.05)$; otherwise, Kruskal-Wallis test and multiple comparisons of groups were performed (IBM Statistics SPSS 25.0 per Windows).

\section{Results}

Kernels of genotypes adopted in this study differ for their appearance, starch composition and pigment accumulation (Fig. 1).

The comparison between emerged adults in sul and $y 1$ mutant and relative wild-type seeds (Tables 1,2), as well as between colored and colorless seeds (Table 3), did not show any significant differences.

An additional analysis was performed by comparing the data obtained from the three different genetic lines among themselves, without considering the homozygous mutant seeds. In this comparison, we include three additional

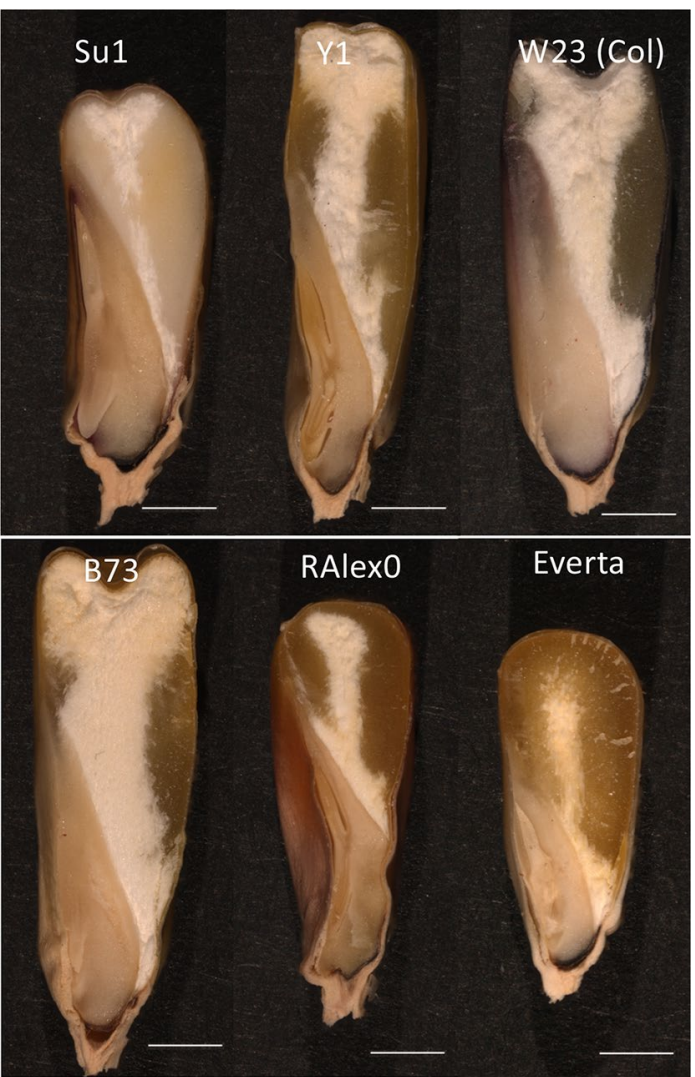

Fig. 2 Sectioned wild-type kernels. In the sectioned kernels, the vitreous region appears lucid and darker, while the floury region is white and opaque (white bar: $3 \mathrm{~mm}$ in length)

Table 4 Adults of Rhyzopertha dominica $( \pm \mathrm{SE})$ emerged from the whole and sectioned kernels of different maize genotypes

\begin{tabular}{lllr}
\hline Genotype/line & $\begin{array}{l}\text { Proportion of vitre- } \\
\text { ous endosperm }\end{array}$ & Adults \\
\cline { 3 - 4 } & & Whole & \multicolumn{1}{c}{ Sectioned } \\
\hline B73 & Low & $0.7 \pm 0.48 \mathrm{c}$ & $10.0 \pm 0.41$ \\
$Y 1 /-$ & Intermediate & $1.2 \pm 0.63 \mathrm{bc}$ & $12.0 \pm 1.47$ \\
W23 ACR Col & Intermediate & $4.5 \pm 1.04 \mathrm{ab}$ & $9.2 \pm 2.21$ \\
RAlexo & Large & $2.2 \pm 1.31 \mathrm{bc}$ & $8.2 \pm 2.95$ \\
Su1/Su1 & Large & $3.2 \pm 1.25 \mathrm{bc}$ & $13.5 \pm 1.71$ \\
Popcorn & Large & $7.0 \pm 0.71 \mathrm{a}$ & $13.0 \pm 1.91$ \\
\hline
\end{tabular}

Anova: whole grain $F_{5},{ }_{18}=5.855 \quad P<0.01$; sectioned grain $F_{5,18}=1.336 P=0.294$ n.s. Values followed by different letters are significantly different (LSD test)

genotypes, i.e., the reference line B73, the RAlexo line, and the popcorn variety.

All these genotypes are characterized by endosperm with a different texture (Fig. 2; Table 4). The B73 seeds show a high proportion of starchy endosperm and low presence of vitreous endosperm. In the rest of the genotypes, there is a higher presence of vitreous endosperm. RAlexo seeds have 
a large proportion of vitreous endosperm and are characterized by the presence of a large embryo. The vitreous region is particularly abundant in the endosperm of the popcorn variety, which can thus be classified as hard endosperm (Larkins et al. 2017).

Despite the difference in the endosperm texture, we did not observe any statistically significant differences in the number of adults developed from sectioned seeds. Statistically significant differences were instead observed in the whole seeds test. The lowest value was observed for the B73 line and the highest for the popcorn variety. These two genotypes have the lowest and highest proportions of vitreous endosperm, respectively.

Data on development days are reported in Table 1S. Even if data on the days required to complete the development from neonate larva to adult on whole kernels are normally distributed, the presence of heterogeneous numbers weakened the statistical analysis. Data on development on sectioned kernels do not present a normal distribution, and this prevented the possibility of comparing them with those on whole kernels.

\section{Discussion}

Our results indicate that differences in the susceptibility to Rhyzopertha dominica attack may not be attributable to variations in single genes affecting specific traits, such as starch composition and pigment accumulation in the host plant. Differences were observed when different genetic backgrounds were compared. This suggests that the susceptibility to this insect attack might be attributable to quantitative traits, such as kernel texture and nutrient composition, which are controlled by multiple genetic factors.

At present, different maize genotypes have been developed to meet different nutritional and usage demands. Selection and genetic improvement have led to different quality and quantity of seed storage molecules and therefore to different seed hardness. Hard, flint maize varieties, with a large proportion of vitreous endosperm, are often considered to be often more resistant than soft, floury varieties, in which the proportion of vitreous endosperm is very low. It has been proposed that the vitreous endosperm strengthens the kernel making it less fragile. The hardness of seeds has been demonstrated to affect the successful and rapid multiplication of insect pests in opaque2 (o2) mutants, which do not form vitreous endosperm and thus show a high degree of susceptibility to attack by $S$. zeamais and S. cerealella (Rhine and Staples 1968). Differently, Towes et al. (2000) demonstrated that in rice grain hardness did not influence the reproduction of $R$. dominica.

Accordingly, in our study, in the whole kernels experiment the highest number of adults was observed in the popcorn, which is a hard variety, and the lowest number in the B73 line, which is dent line with high soft starch grain content (Table 4). Our interpretation is that seed hardness does not prevent $R$. dominica attack. In addition, the presence of vitreous endosperm, which is rich in proteins, at the periphery of the popcorn kernels, positively influences insect number. When fed with the protein-rich popcorn, however, $R$. dominica has a longer mean developmental period than on B73 line that is rich in starch (Table 1S).

In sectioned kernels, different ratios of vitreous and floury endosperm did not affect insect number (Table 4). This observation can be explained by the fact that sectioned kernels facilitate the finding of appropriate nutrients.

Susceptibility to insect attack might be investigated more extensively through the comparison of a large number of maize accessions, including landraces and local varieties, as well as modern commercial genotypes. Variations in these traits are envisaged and will be informative for unraveling their complex genetic basis. On this basis, programs aimed at improving the resistance to insect damage can be designed.

Acknowledgements We would like to thank the Maize Genetics Cooperation Stock Center for providing the mutant seed stocks, Dr. Lesley Currah for editing the manuscript, and the anonymous reviewers for their suggestions that improved the manuscript.

\section{Compliance with ethical standards}

Conflict of interest The authors declare that they have no conflict of interest.

Open Access This article is distributed under the terms of the Creative Commons Attribution 4.0 International License (http://creativeco mmons.org/licenses/by/4.0/), which permits unrestricted use, distribution, and reproduction in any medium, provided you give appropriate credit to the original author(s) and the source, provide a link to the Creative Commons license, and indicate if changes were made.

\section{References}

Amos TG, Semple RL, Williams P (1986) Multiplication of some stored grain insects on varieties of wheat. Gen Appl Entomol 18:48-52

Astuti LP, Mudjiono G, Rasminah CS, Rahardjo BT (2013) Susceptibility of milled rice varieties to the Lesser Grain Borer (Rhyzopertha dominica, F.). J Agric Sci (Toronto) 5:145-149

Bell CH, Hole BD, Evans PH (1977) The occurrence of resistance to phosphine in adult and egg stages of strains of Rhyzopertha dominica (F.) (Coleoptera: Bostrichidae). J Stored Prod Res 13:91-94

Bhatia SK, Gupta M (1969) Resistance to stored grain pests in world collection of wheat-relative susceptibility of nine high yielding dwarf varieties to the rice weevil and the lesser grain borer. Bull Grain Technol 7:199-204

Birch LC (1945a) The mortality of the immature stages of Calandra oryzae L. (small strain) and Rhizopertha dominica Fab. in 
wheat of different moisture contents. Aust J Exp Biol Med Sci 23:141-145

Birch LC (1945b) The influence of temperature on the development of the different stages of Calandra oryzae L. and Rhizopertha dominica Fab. (Coleoptera). Aust J Exp Biol Med Sci 23:29-35

Breese MH (1960) The infestibility of stored paddy by Sitophilus sasakii (Tak.) and Rhyzopertha dominica (F.). Bull Entomol Res 51:599-630

Buckner B, San Miguel P, Janick-Buckner D, Bennentzent J (1996) The $y 1$ gene of maize codes for phytoene synthase. Genetics 143:480-488

Campbell A, Sinha RN (1976) Damage of wheat by feeding of some stored product beetles. J Econ Entomol 69:11-13

Chanbang Y, Arthur FH, Wilde GE, Throne JE (2008a) Hull characteristics as related to susceptibility of different varieties of rough rice to Rhyzopertha dominica (F.) (Coleoptera: Bostrichidae). J Stored Prod Res 44:205-212

Chanbang Y, Arthur FH, Wilde GE, Throne JE, Subramanyam BH (2008b) Methodology for assessing rice varieties for resistance to the lesser grain borer, Rhyzopertha dominica. J Insect Sci 8:16

Chougourou DG, Togola A, Nwilene FE, Adeliossi J, Bachabi F, Oyetunji OE (2013) Susceptibility of some rice varieties to the lesser grain borer, Rhyzopertha dominica Fab. (Coleoptera: Bostrichidae) in Benin. J Appl Sci 13:173-177

Collins PJ (1998) Resistance to grain protectants and fumigants in insect pests of stored products in Australia. In: Banks HJ, Wright EJ, Damcevski KA (eds) Stored grain in Australia. Proceedings of the Australian post-harvest technical conference. CSIRO, Canberra, pp 55-57

Collins DA (2006) A review of alternatives to organophosphorus compounds for the control of storage mites. J Stored Prod Res 42:395-426

Collins PJ, Lambkin TM, Bridgeman BW, Pulvirenti C (1993) Resistance to grain-protectant insecticides in coleopterous pests of stored cereals in Queensland, Australia. J Econ Entomol 86:239-245

Collins PJ, Falk MG, Nayak MK, Emery RN, Holloway JC (2017) Monitoring resistance to phosphine in the lesser grain borer, Rhyzopertha dominica, in Australia: a national analysis of trends, storage types and geography in relation to resistance detections. J Stored Prod Res 70:25-36

Consonni G, Gavazzi G, Dolfini S (2005) Genetic analysis as a tool to investigate the molecular mechanism underlying seed development in maize. Ann Botany 96:353-362

Daglish GJ, Holloway JC, Nayak MK (2013) Implications of methoprene resistance for managing Rhyzopertha dominica $(\mathrm{F}$.) in stored grain. J Stored Prod Res 54:8-12

Dooner HK, Robbins TP, Jorgensen RA (1991) Genetic and developmental control of anthocyanin biosynthesis. Annu Rev Genet 25:173-199

Edde PA (2012) A review of the biology and control of Rhyzopertha dominica (F.) the lesser grain borer. J Stored Prod Res 48:1-18

El Halfawy MA, Hassan HI (1978) The relative susceptibility of certain varieties of wheat, maize and barley to infestation with the lesser grain borer, Rhizopertha dominica F. Agric Res Rev 56:165-169

Erwin AT (1949) The origin and history of popcorn, Zea mays L. var. indurata (Sturt.) Bailey mut. everta (Sturt.) Erwin. Agron J 41:53-56

Gavazzi G, Stucchi C, Pilu R (2004) The al-eap allele of A1 represents a specific marker for the selection of embryogenetic mutants. Maize News Lett 78:40-41

Gerdes JT, Behr CF, Coors JG, Tracy WF (1993) Compilation of North American maize breeding germplasm. Misc. Publ. CSSA, Madison
Goldman IL, Rocheford TR, Dudley JW (1994) Molecular markers associated with maize kernel oil concentration in an Illinois High Protein X Illinois Low Protein cross. Crop Sci 34:908-915

Guedes RNC, Dover BA, Kambhampati S (1996) Resistance to chlorpyrifos-methyl, pirimiphos-methyl, and malathion in Brazilian and U.S. populations of Rhyzopertha dominica (Coleoptera: Bostrichidae). J Econ Entomol 89:27-32

Guedes RNC, Kambhampati S, Dover BA (1997) Organophosphate resistance and its biochemical mechanisms in Brazilian and U.S. populations of the lesser grain borer, Rhyzopertha dominica. Resist Pest Manag Newsl 9:24-25

Herron GA (1990) Resistance to grain protectants and phosphine in coleopterous pests of grain stored on farms in New South Wales. Aust J Entomol 29:183-189

Howe RW (1950) The development of Rhyzopertha dominica (F.) (Coleoptera: Bostrichidae) under constant temperature. Entomol Mon Mag 86:1-5

James MG, Robertson DS, Myers AM (1995) Characterisation of the maize gene sugary 1, a determinant of starch composition in kernels. Plant Cell 7:417-429

Kavallieratos NG, Athanassiou CG, Arthur FH, Throne JE (2012) Lesser grain borers, Rhyzopertha dominica, select rough rice kernels with cracked hulls for reproduction. J Insect Sci 12:38

Kurdikeri MB, Aswathaiah B, Katagall RD, Rajendraprasad S, Vasudevan S (1994) Laboratory studies on extent of seed damage, loss in weight and viability due to infestation of the lesser grain borer (Rhizopertha dominica Fabr.) in maize hybrids. Karnataka J Agric Sci 7:186-189

Kurdikeri MB, Aswathaiah B, Rajendraprasad S, Katgal RD, Aswatharayana SC (1995) Studies on relative seed damage-loss in weight and loss of viability caused by Sitophilus oryzae Linn. and Rhizopertha dominica Fabr. in maize hybrids. Seed Res 21:72-77

Larkins BA, Wu Y, Song R, Messing J (2017) Maize seed storage proteins. In: Larkins BA (ed) Maize kernel development. CAB International, Wallingford, pp 175-189

Li J, Berger F (2012) Endosperm: food for humankind and fodder for scientific discoveries. N Phytol 195:290-305

Limonta L, Morosini MC, Locatelli DP (2011) Development of Rhyzopertha dominica (F.) (Coleoptera: Bostrichidae) on durum wheat kernels and semolina. J Entomol Acarol Res 43:33-38

Lorini I, Collins PJ (2006) Resistance to phosphine in Rhyzopertha dominica (F.) (Coleoptera: Bostrychidae) collected from wheat storages in Brazil. In: Lorini I, Bacaltchuk, B, Beckel H, Deckers D, Sundfeld E, dos Santos JP, Biagi JD, Celaro JC, Faroni LRDA, Bortolini L, Sartori MR, Elias MC, Guedes RNC, da Fonseca RG, Scussel VM (Eds) Proceedings of the 9th international working conference on stored-product protection, 15 to 18 October 2006. Campinas, São Paulo, pp 319-323

Lorini I, Galley DJ (1996) Changes in resistance status of Rhyzopertha dominica (F.) (Coleoptera: Bostrychidae), a pest of stored grain in Brazil, with and without deltamethrin selection. Resist Pest Manag News1 8:12-14

Lorini I, Galley DJ (1999) Deltamethrin resistance in Rhyzopertha dominica (F.) (Coleoptera: Bostrichidae), a pest of stored grain in Brazil. J Stored Prod Res 35:37-45

Navarro S, Carmi Y, Kashanchi Y, Shaaya E (1986) Malathion resistance of stored product insects in Israel. Phytoparasitica $14: 273-280$

Opit GP, Phillips TW, Aikins MJ, Hasan MM (2012) Phosphine resistance in Tribolium castaneum and Rhyzopertha dominica from stored wheat in Oklahoma. J Econ Entomol 105:1107-1114

Pan D, Nelson OE (1984) A debranching enzyme deficiency in endosperm of the 7 Sugary mutants of maize. Plant Physiol $74: 324-328$ 
Pandey NO, Singh LN (1974) Studies on relative resistance of some maize varieties to Rhizopertha dominica Fabr. Bull Grain Technol 12:29-31

Parkin EA (1965) The onset of insecticide resistance among field populations of stored-product insects. J Stored Prod Res 1:1-38

Rhine JJ, Staples R (1968) Effect of high-amylose field corn on larval growth and survival of 5 species of stored-grain insects. J Econ Entomol 61:280-282

Russell WA (1972) Registration of B70 and B73 parental lines of maize. Crop Sci 12:721

Schnable PS, Ware D, Fulton R, Stein J, Wei F et al (2009) The B73 maize genome: complexity, diversity, and dynamics. Science 326:1112-1115

Singh LN, Pandey ND (1977) Correlation studies between insect population, percentage of damage and loss in weight of maize varieties due to Rhizopertha dominica F. and Sitotroga cerealella Oliv. Indian J Entomol 37:239-242

Sinha RN, Demianyk CJ, McKenzie RIH (1988) Vulnerability of common wheat cultivars to major stored product beetles. Canad J Plant Sci 68:337-343

Tan BC, Schwartz SH, Zeevaart JA, McCarty DR (1997) Genetic control of abscisic acid biosynthesis in maize. Proc Natl Acad Sci USA 94:12235-12240

Throne JE, Baker JE, Messina FJ, Kramer KJ, Howard JA (2000) Varietal resistance. In: Subramanyam B, Hagstrum DW (eds)
Alternatives to pesticides in stored product IPM. Kluwer Academic Publishers, Dordrecht, pp 167-192

Towes MD, Cuperus GW, Phillips TW (2000) Susceptibility of eight U.S. wheat cultivars to infestation by Rhyzopertha dominica (Coleoptera: Bostrichidae). Environ Entomol 29:250-255

Watts VM, Dunkel FV (2003) Postharvest resistance in hard spring and winter wheat varieties of the Northern Great Plains to the lesser grain borer (Coleoptera: Bostrichidae). J Econ Entomol 96:220-230

Winterbottom DC (1922) Weevil in wheat and storage of grain in bags. A record of Australian experience during the War Period (1915 to 1919). Government Printer, North Terrace, Adelaide

Zettler LJ, Cuperus GR (1990) Pesticide resistance in Tribolium castaneum (Coleoptera: Tenebrionidae) and Rhyzopertha dominica (Coleoptera: Bostrichidae) in wheat. J Econ Entomol 83:1677-1681

Publisher's Note Springer Nature remains neutral with regard to jurisdictional claims in published maps and institutional affiliations. 